\title{
Bacterial Profile, Antibacterial Resistance Pattern, and Associated Factors from Women Attending Postnatal Health Service at University of Gondar Teaching Hospital, Northwest Ethiopia
}

\author{
Abebaw Bitew Kifilie ${ }^{1 D},{ }^{1}$ Mulat Dagnew, ${ }^{2}$ Birhanemeskel Tegenie, ${ }^{2}$ \\ Biruk Yeshitela, ${ }^{3}$ Rawleigh Howe, ${ }^{3}$ and Ebba Abate $^{4}$ \\ ${ }^{1}$ Department of Medical Laboratory Science, College of Medicine and Health Sciences, Debre Markos University, \\ Debre Markos, Ethiopia \\ ${ }^{2}$ Department of Medical Microbiology, School of Biomedical and Laboratory Science, \\ College of Medicine and Health Science, University of Gondar, Gondar, Ethiopia \\ ${ }^{3}$ Armauer Hansen Research Institute, Addis Ababa, Ethiopia \\ ${ }^{4}$ Department of Immunology and Molecular Biology, School of Biomedical and Laboratory Science, \\ College of Medicine and Health Science, University of Gondar, Gondar, Ethiopia
}

Correspondence should be addressed to Abebaw Bitew Kifilie; abebawbit05@gmail.com

Received 23 July 2017; Accepted 12 November 2017; Published 25 February 2018

Academic Editor: Joseph Falkinham

Copyright (c) 2018 Abebaw Bitew Kifilie et al. This is an open access article distributed under the Creative Commons Attribution License, which permits unrestricted use, distribution, and reproduction in any medium, provided the original work is properly cited.

\begin{abstract}
Introduction. Surgical site infection is a vital cause of maternal mortality and morbidity, especially in resource-limited countries. The rise of antibiotic resistance bacterial infection poses a big threat to this vulnerable population. However, there is lack of studies around the study area. Objective. The purpose of this study was to identify bacterial profile, antibacterial resistance pattern, and associated factors among mothers attending postnatal care health service. Methods. Institutional based cross-sectional study was conducted on 107 study participants at University of Gondar Teaching Hospital from 1 January 2016 to 30 May 2016. Wound swab, aspirate, and biopsy were collected and performed for culture and drug resistance testing. Data were entered and analyzed by using SPSS version 20. Bivariate and multivariate logistic regression models were fitted to determine the associated factors for bacterial infection. Odds ratio ( $95 \% \mathrm{CI}$ ) was calculated to determine the strength of statistically significant associated factors. Result. Bacterial growth was confirmed in 90 (84.1\%) of 107 study participants suspected to have surgical site infection. The predominant bacterial isolates were S. aureus (41.6\%), E. coli (19.8\%), K. pneumoniae (13.9\%), coagulase negative Staphylococcus (12.9\%), and Enterobacter spp. (4\%). The majority of isolates were resistant to ampicillin, amoxicillin, and tetracycline but susceptible to ceftriaxone and amikacin. Multidrug-resistant bacteria species were isolated. Using a procedure such as cesarean section and episiotomy for delivery and premature rapture of membrane had strong association with bacterial infection. Conclusion. The high prevalence of bacterial profile and isolation of multidrug-resistant bacteria pose a big threat to postnatal mothers and their children. Factors such as cesarean section, episiotomy for delivery, and premature rapture of membrane were predictors for bacterial infection. Therefore, there should be done a continuous surveillance as well as rational use of antibiotics and a longitudinal study using phenotypic and genotypic methods will be done.
\end{abstract}

\section{Introduction}

Surgical site infection (SSI) is an infection that occurs on the skin and subcutaneous tissue within 30 days of surgical incision or deep tissue surgical procedure [1]. It is characterized by the basic sign of redness, pain, swelling, raised incision tissue temperature, and systemic fever $[2,3]$. It also causes infection to women pelvic organs when normal flora 
of the women's genital and gastrointestinal tract contaminates the sterile amniotic fluid [4]. Women who give birth by cesarean section delivery have 5 -fold to 20 -fold risk of bacterial infection than women who give birth vaginally [5]. The predominant pathogenic bacteria isolated from infected wound include Escherichia coli (E. coli), Streptococcus species, Enterococcus faecalis (E. faecalis), Staphylococcus aureus (S. aureus), Coagulase negative Staphylococcus (CoNS), Gardnerella vaginalis, and genital mycoplasmas $[6,7]$. Bacteria that are isolated from SSI are too common to resist multiple classes of antibiotics. The downfall of efficient antibacterials will weaken our capacity to manage contagious disease in vulnerable patients undergoing cesarean section delivery [8]. World health leaders have declared that antibiotic-resistant bacteria are hurtful bacteria that cause a devastating risk to people in the world [9].

Generally bacterial infections during cesarean section delivery are among the principal sources of maternal mortality, which accounts for nearly one-tenth of global maternal death [10]. Annually the global estimate of SSIs is from $0.5 \%$ to $15 \%$; this leads to an estimate of 358,000 maternal deaths in the world, of which $99 \%$ were in developing countries and half of which were in Sub-Saharan Africa; besides death, women who are exposed to peripartum infections are at risk of severe morbidity and long-term disabilities such as chronic pelvic pain, fallopian tube blockage, secondary infertility, and prematurity of the child $[11,12]$. The risk of SSI was associated with premature rupture of membranes, prolonged labour, malnutrition, diabetes mellitus, obesity, lack of preincision antimicrobial care, which increases patients hospital stay, readmission, cost of care, and mortality $[13,14]$. Decreasing the number of deliveries by $\mathrm{C} / \mathrm{S}$ and identifying associated factors for SSI could contribute to decreasing maternal morbidity $[7,15]$.

Screening and treating bacterial infection during postnatal periods can improve future pregnancy and delivery outcomes. However, as far as our knowledge is concerned, there is a lack of studies conducted on bacterial profile and antibiotic susceptibility pattern among women attending postnatal service in developing countries including Ethiopia; as a result, the magnitude is not well known and is not comprehensive. To confirm proper treatment, recent information about organism, source of maternal infection, and its drug sensitivity test is mandatory. The information compiled here will increase the awareness of significant bacterial infection during postnatal periods, so periodic evaluation of bacterial profile and its drug response is needed to bring updated information. Therefore, this study determines bacterial profile, antibacterial susceptibility pattern, and associated factors among women attending postnatal health services.

\section{Materials and Methods}

2.1. Study Design, Area, and Period. An institutional based cross-sectional study was conducted at University of Gondar Teaching Hospital from January 2016 to May 2016. Gondar town is located $738 \mathrm{~km}$ far away from Addis Ababa, the capital city of Ethiopia.
2.2. Sample Size and Sampling Technique. A total of 107 women who have an infection due to cesarean section (CS) and episiotomy delivery were self-reporting to the hospital and were sampled for laboratory culture confirmation during the study period.

2.3. Sociodemographic Data and Specimen Collection. Sociodemographic variables such as age, residence, marital status, educational level, and occupation and other relevant clinical data such as gravidity, parity, and mode of delivery were collected using structured questionnaire. The specimen was collected by trained midwife nurses after getting ethical clearance from the School of Biomedical and Laboratory Science ethical review committee and informed written consent from study participants. Each biological specimen was collected for bacteriological laboratory analysis such as culture, Gram stain, biochemical test, and antibacterial susceptibility test.

\subsection{Wound Specimen Collection and Laboratory Processing.} The area around surgical and episiotomy site was cleaned with normal saline in order to reduce contamination. Then 107 wound specimens were collected by wound swabbing, Levine technique, and Z-technique by using sterile cotton tipped applicator stick, aspirating by needle and cutting wound biopsy depending on the wound type. Wound exudates were collected prior to wound cleaning during swabbing, but in Levine technique and Z-technique wound exudates were collected after wound cleaning.

Wound swabbing using Levine technique involves the rotation of swab over $1 \mathrm{~cm}^{2}$ area with sufficient pressure to fast fluid release from wound, whereas $Z$-technique requires the rotation of swab between 2 fingers by zigzag motion from margin to margin of wound at 10 points $[16,17]$.

Cotton tipped applicator stick that contains specimen was socked to a test tube containing Tryptone Soya broth in order to prevent drying and transported to microbiology laboratory.

The sample was inoculated onto blood agar plate (BAP) (Oxoid), MacConkey agar (MaC) (Oxoid), and Mannitol Salt Agar (MSA) (Oxoid) and incubated aerobically for 18-24 hours at $37^{\circ} \mathrm{C}$. Identification of bacteria was performed based on colony morphology such as size, pigment, and edge with the naked eye from culture media and Gram stain. Gram stain was used to distinguish Gram-positive and Gram-negative isolates. Biochemical characteristics such as catalase, coagulase, bacitracin, novobiocin, and optochin were used to identify Gram-positive pathogenic bacterial species, whereas triple sugar iron agar, indole test, motility test, urea test, hydrogen sulfide production, citrate test, and lysine decarboxylase test results were used to identify Gram-negative pathogenic bacterial species.

2.5. Antibacterial Susceptibility Test. Antibacterial susceptibility testing was done by using modified Kirby-Bauer disk diffusion method and interpreted according to Clinical and Laboratory Standard Institute (CLSI, 2016) guidelines [18]. Around 3-5 pure colonies of bacteria were taken and transferred to a tube containing $5 \mathrm{ml}$ sterile nutrient broth (Oxoid) and mixed gently until a homogenous suspension was formed 
and incubated for 3-5 hours until the turbidity of the suspension becomes adjusted to the density of $0.5 \%$ McFarland standards. Then they were inoculated to Müller-Hinton agar (MHA, $\mathrm{PH}=7.2-7.4$ ) (Oxoid) by using sterile swab evenly with $60^{\circ}$. The inoculums were allowed to dry for 5-15 minutes. Antibacterial discs were distributed $15 \mathrm{~mm}$ away from the edge and $\geq 24 \mathrm{~mm}$ apart from each other.

Antibiotic discs penicillin (10 IU), cloxacillin $(30 \mu \mathrm{g})$, tetracycline $(30 \mu \mathrm{g})$, clindamycin $(2 \mu \mathrm{g})$, gentamycin $(10 \mu \mathrm{g})$, nalidixic acid $(30 \mu \mathrm{g})$, ciprofloxacin $(5 \mu \mathrm{g})$, amikacin $(30 \mu \mathrm{g})$ ampicillin $(10 \mu \mathrm{g})$, amoxicillin $(10 \mu \mathrm{g})$, cefoxitin $(30 \mu \mathrm{g})$, cefixime $(5 \mu \mathrm{g})$, ceftriaxone $(30 \mu \mathrm{g})$, trimethoprim sulfamethoxazole $(1.25 / 23.75 \mu \mathrm{g})$, and ceftazidime $(30 \mu \mathrm{g})$ were used for SSI. Then the plates were incubated at $37^{\circ} \mathrm{C}$ for 24 hours and the results were interpreted according to the most recent version of Clinical Laboratory Standard Institute (CLSI 2016) [18]. The criteria to select the antimicrobial agents were based on availability, CLSI guide line, the organisms' Gram reaction, and frequent prescription of drugs for the management of postnatal infections.

2.6. Data Management, Analysis, and Presentation. The collected data were coded and transferred from a questionnaire to a computer file. Data were entered and statistically analyzed by SPSS version 20 software. Descriptive statistics were used to analyze frequency, mean, range, and standard deviation of sociodemographic characteristics and obstetric and clinical variables of study. Tables and figures were used to present the findings.

Bivariate and multivariate logistic regression models were fit to determine possible associated factors with bacterial infection. Odds ratio was used as a measure of the strength of association and reported with 95\% confidence intervals (95\% $\mathrm{CI})$ to determine statistically significant association of risk factors with bacterial infection. $p$ value $\leq 0.05$ was considered to be statistically significant.

2.7. Data Quality Control. All steps in data collection and recording were monitored. The reagents were checked for expiry date and appropriate storage of temperature and humidity. SOPs were prepared and strictly followed. The quality of culture media and antimicrobial susceptibility testing was checked by using quality control standard strains of $E$. coli ATCC 25922, S. aureus ATCC 25923, E. faecalis ATCC 29212, and K. pneumoniae ATCC ${ }^{\circledR}$ BAA1705. 0.5\% McFarland standards were used to standardize the inoculum density of bacterial suspension for susceptibility test. The acceptance range of $0.5 \%$ McFarland optical density is $0.08-0.1$ [18].

2.8. Ethical Consideration. Ethical clearance was obtained from University of Gondar, School of Biomedical and Laboratory Sciences (SBMLS) ethical review committee for the initiation of the study. There was no additional sample to be taken from the study participants but only for the sake of this study. A written informed consent was obtained from mothers after explaining the purpose and objective of the study to them. Participants would have full right to continue or

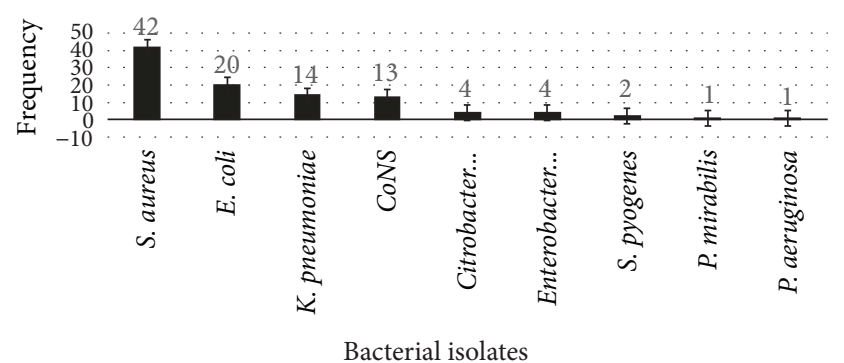

FIGURE 1: Profile and frequency of bacterial isolates from women having SSI during postnatal period at the University of Gondar Teaching Hospital from 1 January 2016 to 30 May 2016.

withdraw from the study. All information was kept confidential by assigning code and assessed only by principal investigator. The laboratory results were communicated timely with physicians and nurses for better patient management.

\section{Result}

3.1. Sociodemographic, Obstetric, and Clinical Variables. A total of 107 women with symptoms of infections during postnatal periods were investigated in this study. The mean age of the study participants was $26.21( \pm 5.5)$ and ranged from 15 to 44 . The majority of the participants were urban dwellers (77.6\%), orthodox Christian (90.7\%), married (98.1\%), and housewives (60.7\%). A total of 107 postnatal clinic (PNC) participants were delivered from health institution, 52 (48.6\%) of them had history of prolonged labour, $43(40.2 \%)$ had history of premature rapture of membrane, and 81 (48.5\%) were delivered cesarean section. Most of those participants had a history of 1-3 gravida (88.8\%) (Table 1).

3.2. Isolation of Pathogenic Bacteria from SSI. Of all the study participants, 107 wound specimens were collected based on physician request at the University of Gondar Teaching Hospital. From these suspected clinical specimens, the overall pathogenic bacterial infections were 90 (84.1\%). Among these, $79(87.8 \%)$ infections were due to single bacterial isolates, whereas 11 (12.2\%) infections were due to mixed bacterial isolates. So a total of 101 bacterial isolates were isolated. Majority of them were Gram-positive and the predominant were S. aureus, 42/101 (41.6\%), and CoNS, 13/101 (12.9\%), followed by Gram-negative E. coli, 20/101 (19.8\%), and K. pneumoniae, 14/101 (13.9\%) (Figure 1).

\subsection{Antibacterial Susceptibility Pattern for Bacterial Pathogen} from SSI. Majority of isolates from SSI were resistant to regularly used antibacterials. S. aureus was resistant to ampicillin (71.4\%), amoxicillin (66.7\%), and trimethoprimsulfamethoxazole (61.9\%). Likewise, CoNS was resistant to ampicillin (84.6\%), amoxicillin (84.6\%), trimethoprimsulfamethoxazole (61.5\%), penicillin (61.5\%), cloxacillin (38.5\%), and cefoxidime (38.5\%). In contrast, clindamycin (84.2\%), cefoxitin (82.5\%), cefixime (73.7\%), and ceftriaxone (68.4\%) were susceptible to Gram-positive isolates (Table 2). 
TABLE 1: Sociodemographic, obstetric, and clinical variables from women attending antenatal and postnatal services at the University of Gondar Teaching Hospital from 1 January 2016 to 30 May 2016.

\begin{tabular}{|c|c|}
\hline Characteristics & Number (\%) \\
\hline \multicolumn{2}{|l|}{ Age (years) } \\
\hline $15-24$ & $39(36.5 \%)$ \\
\hline $25-34$ & $56(52.3 \%)$ \\
\hline $35-44$ & $12(11.2 \%)$ \\
\hline \multicolumn{2}{|l|}{ Residence } \\
\hline Urban & $83(77.6 \%)$ \\
\hline Rural & $24(23.4 \%)$ \\
\hline \multicolumn{2}{|l|}{ Religion } \\
\hline Orthodox & $97(90.7 \%)$ \\
\hline Muslim & $7(6.5 \%)$ \\
\hline Protestant & $3(2.8 \%)$ \\
\hline \multicolumn{2}{|l|}{ Marital status } \\
\hline Married & $105(98.1)$ \\
\hline Single & $2(1.9 \%)$ \\
\hline \multicolumn{2}{|l|}{ Educational level } \\
\hline Illiterate & $35(32.7 \%)$ \\
\hline Primary school (1-8) & $14(13.1 \%)$ \\
\hline Secondary school & $31(29.0 \%)$ \\
\hline Higher education & $27(25.2 \%)$ \\
\hline \multicolumn{2}{|l|}{ Occupational status } \\
\hline Housewives & $65(60.7 \%)$ \\
\hline Self-employees & $17(15.9 \%)$ \\
\hline Government employees & $20(18.7 \%)$ \\
\hline Students & $3(2.8 \%)$ \\
\hline Daily laborer & $2(1.9 \%)$ \\
\hline \multicolumn{2}{|l|}{ Gravidity } \\
\hline $1-3$ & $95(88.8 \%)$ \\
\hline $4-6$ & $10(9.3 \%)$ \\
\hline $7-9$ & $2(1.9 \%)$ \\
\hline \multicolumn{2}{|l|}{ Prolonged labour } \\
\hline Yes & $52(48.6)$ \\
\hline No & $55(51.4 \%)$ \\
\hline \multicolumn{2}{|c|}{ Premature rapture of membrane } \\
\hline Yes & $43(40.2 \%)$ \\
\hline No & $64(59.8 \%)$ \\
\hline \multicolumn{2}{|l|}{ Mode of delivery } \\
\hline Vaginal delivery & $69(41.3 \%)$ \\
\hline Cesarean delivery & $81(48.5 \%)$ \\
\hline Instrumental delivery & $17(10.2 \%)$ \\
\hline \multicolumn{2}{|l|}{ Place of delivery } \\
\hline Health institution & $107(100 \%)$ \\
\hline \multicolumn{2}{|l|}{ Diabetes mellitus } \\
\hline No & $98(91.6 \%)$ \\
\hline Yes & $9(8.4 \%)$ \\
\hline \multicolumn{2}{|l|}{ HIV/AIDS } \\
\hline No & $103(96.3 \%)$ \\
\hline Yes & $4(3.7 \%)$ \\
\hline
\end{tabular}

HIV: human immunodeficiency virus.

On the other hand, Gram-negative isolates were resistant to ampicillin (88.6\%), amoxicillin (79.5\%), and trimethoprim-sulfamethoxazole $(54.5 \%)$. E. coli was resistant to ampicillin (80\%), amoxicillin (70\%), and ceftriaxone (60\%). $K$. pneumoniae was shown to be resistant to ampicillin (100\%), amoxicillin (100\%), trimethoprim-sulfamethoxazole (64.3\%), ceftriaxone (57.1\%), ceftazidime (28.6\%), gentamycin (21.4\%), and ciprofloxacin (14.3\%). Citrobacter spp. were resistant to ampicillin (100\%). In contrast, most Gramnegative isolates were susceptible to amikacin (95.5\%) and ciprofloxacin $(83.7 \%)$ (Table 3$)$.

3.4. Multidrug Resistance Pattern of Bacterial Pathogens. Taking all bacterial isolates from SSI sample were shown $75 \%$ and $82.5 \%$ multidrug resistance $(\mathrm{MDR}=$ resistance of $\geq 2$ drugs with different classes) for Gram negative and Gram positive bacteria respectively. Gram-negative bacteria such as $K$. pneumoniae were $12(85.7 \%)$ resistant to $\geq 2$ drugs in different class. Likewise, CoNS were $11(84.6 \%)$ resistant to $\geq 2$ drugs in different class (Table 4 ).

3.5. Characteristics of Risk Factors Attributed to Bacterial Infections. In bivariate logistic analysis, demographic and clinical factors such as age, occupation, level of education, gravidity, parity, prolonged labour, and history of diabetes mellitus were not significantly associated with bacterial infection in this study; however, mode of delivery and premature rapture of membrane were strongly associated in both bivariate and multivariate analyses for bacterial infection $(p \leq$ $0.05)$. Delivery by cesarean section and episiotomy were 102 and 86 times at risk for bacterial infection than instrumental deliveries $($ AOR $(95 \% \mathrm{CI})=102(5.2,2038, p=0.002)$ and 86 $(5,1436, p=0.002)$, resp.) (Table 5).

\section{Discussion}

Maternal infection during postnatal period was a vital factor for morbidity and mortality [3, 19]. In the current study, the possible etiologic agents causing morbidity among mothers during postnatal period were isolated. Three different biological wound specimens such as wound swab, aspirate, and biopsy were collected to ascertain possible pathogenic bacteria. From this study, the total prevalence of confirmed bacteria was $84.1 \%$. This showed that women who delivered by cesarean section and episiotomy were vulnerable to various bacterial infections and this has continued even after delivery up to 30 days [1]. Considering the fact that postnatal women are part of vulnerable population and the effect could also influence the health status of the neonates, the current finding has shown high public health consequence. This is similar to studies conducted in Ethiopia and elsewhere [2, 2022].

In the current study, the rate of pathogenic bacteria which were isolated from postnatal women was highly considerable for SSI. The predominant pathogens that cause SSIs are $S$. aureus, E. coli, K. pneumoniae, and CoNS. The reason for the predominance of those organisms may be the fact that most of the infected patients in this study had undergone cesarean section and episiotomy procedure for delivery which is favorable for different bacterial colonization commonly reported during SSI $[3,4]$. This study was in line with studies 
TABLE 2: Antibacterial susceptibility pattern for Gram-positive SSI causing pathogens from women attending postnatal service at University of Gondar Teaching Hospital from 1 January 2016 to 30 May 2016.

\begin{tabular}{|c|c|c|c|c|c|c|c|c|c|c|c|}
\hline \multirow{2}{*}{ Bacterial isolates } & & \multicolumn{10}{|c|}{ Antibacterial susceptibility pattern } \\
\hline & & AMP & $\mathrm{AMO}$ & $\mathrm{CRO}$ & $\mathrm{P}$ & CAZ & SXT & CXM & $\mathrm{CXC}$ & DA & CXT \\
\hline \multirow{2}{*}{ S. aureus $(n=42)$} & $\mathrm{S} \%$ & $12(28.6)$ & $14(33.3)$ & $27(64.3)$ & $21(50)$ & $24(57.1)$ & $16(38.1)$ & $31(73.8)$ & $20(47.6)$ & $35(83.3)$ & $35(83.3)$ \\
\hline & $\mathrm{R} \%$ & $30(71.4)$ & $28(66.7)$ & $15(35.7)$ & $21(50)$ & $18(42.9)$ & $26(61.9)$ & $11(26.2)$ & $22(52.4)$ & $7(16.7)$ & $7(16.7)$ \\
\hline \multirow{2}{*}{$\operatorname{CoNS}(n=13)$} & $\mathrm{S} \%$ & $2(15.4)$ & $2(14.3)$ & $8(61.5)$ & $5(38.5)$ & $8(61.5)$ & $5(38.5)$ & $10(76.9)$ & $8(61.5)$ & $12(92.3)$ & $11(84.6)$ \\
\hline & $\mathrm{R} \%$ & $11(84.6)$ & $11(85.7)$ & $5(38.5)$ & $8(61.5)$ & $5(38.5)$ & $8(61.5)$ & $3(23.1)$ & $5(38.5)$ & $1(7.7)$ & $2(15.4)$ \\
\hline \multirow{2}{*}{ S. pyogenes $(n=2)$} & $\mathrm{S} \%$ & $0(0)$ & $1(50)$ & $4(100)$ & $2(100)$ & $1(50)$ & $1(50)$ & $1(50)$ & $1(50)$ & $1(50)$ & $1(50)$ \\
\hline & $\mathrm{R} \%$ & $2(100)$ & $1(50)$ & $0(0)$ & $0(0)$ & $1(50)$ & $1(50)$ & $1(50)$ & $1(50)$ & $1(50)$ & $1(50)$ \\
\hline \multirow{2}{*}{ Total $(n=57)$} & $S \%$ & $14(24.6)$ & $17(29.8)$ & $39(68.4)$ & $28(49.1)$ & $33(57.9)$ & $22(38.6)$ & $42(73.7)$ & $29(50.9)$ & $48(84.2)$ & 47 (82.5) \\
\hline & $R \%$ & $43(75.4)$ & $40(70.2)$ & $18(31.6)$ & $29(50.9)$ & $24(42.1)$ & $35(61.4)$ & $15(26.3)$ & $28(49.1)$ & $9(15.8)$ & $10(17.5)$ \\
\hline
\end{tabular}

P: penicillin; CAZ: ceftazidime; CXM: cefixime; CXC: cloxacillin; CD: clindamycin; CXT: cefoxitin; S. pyogenes: Streptococcus pyogenes.

conducted in Bahir Dar (83.3\%) [9], Addis Ababa (84.1\%) [3], and Nizwa Hospital, Oman (77.72\%) [23]. But the current findings were higher compared to studies conducted in Gondar (31.5\%) [24], Tanzania (61.8\%) [22], Nepal (62.4\%) [5], and Estonian University (6.2\%) [7]. The possible explanation for this discrepancy might be due to poor wound care and aseptic technique during $\mathrm{C} / \mathrm{S}$ and episiotomy procedure.

It is known that, from wound, there are different microbial contaminations. Wound cleaning without regular handwashing antiseptics such as $70 \%$ alcohol and/or normal saline worsens the complications. To prevent further contamination, cleaning wounds with normal saline, covering with clean and dry bandage, giving patient education about personal hygiene, avoiding cross infection by restricting visitors, providing routine education regarding infection control measures, and following necessary SOP during sample collection should be applied [23]. The prevalence of pathogenic bacteria from wound was different, even though the study participants were similar. The difference might be related to accessibility of diagnostic materials, the use of aseptic technique during sample processing, and sample size. A study showed in Jimma [14] that the specimens were collected from women infected due to cesarean section for delivery including ovarian tumor operation and Myoma, but in the present study the specimens were collected from women infected due to cesarean section and episiotomy delivery.

Nowadays, emerging of high rate of bacteria resistant to multiple antibiotics is becoming a global threat by crossing worldwide borders and spreading between regions with significant speed. World health leaders have declared that drug-resistant organisms are frightening organisms that have a disastrous risk to persons in each country in the world [25]. Several factors augment this problem. Understanding bacterial profile and its antibiotic pattern is of paramount importance for proper management and minimizing the circulation of common pathogenic resistance strains in the community [13]. In this study, we tried to assess the sensitivity pattern of the isolated bacteria to different drugs in vitro. In the present finding, S. aureus, E. coli, CoNS, and K. pneumoniae are the commonest pathogens isolated from wound and were resistant to many antibiotics, indicating the big threat they poses. On the other hand, Gram-negative bacteria were susceptible to strong antibiotics like amikacin, ciprofloxacin, and others. This result is similar to studies in Bahir Dar [9], Addis Ababa [3], Mek'ele [26], and Palestine [19]. However, as long as there is high rate of irrational use of antibiotics as well as poor adherence in the society, these antibiotics may no longer be effective to pathogens. Different antibacterial susceptibility patterns were observed for bacterial isolates collected from wound sites. One of the commonest isolated bacteria from wound site was $S$. aureus, which was resistant to ampicillin (71.4\%), amoxicillin (66.7\%), and trimethoprimsulfamethoxazole (61.9\%). More or less this is in agreement with a study done in Bahir Dar [9]. Similarly, CoNS was highly resistant to ampicillin (84.6\%), amoxicillin (84.6\%), and trimethoprim-sulfamethoxazole (63.6\%). This is in agreement with a study done in Bahir Dar [9]. Among Gramnegative bacteria, E. coli was highly resistant to ampicillin $(80 \%)$, amoxicillin (70\%), and ceftriaxone (60\%). This finding is in line with a study done in Addis Ababa [3,23]. In addition, $K$. pneumoniae was shown to be fully resistant to amoxicillin (100\%) and ampicillin (100\%) and strongly resistant to trimethoprim-sulfamethoxazole (64.3\%) and ceftriaxone (57.1\%). This is in agreement with a study done in Addis Ababa and Debre Markos [3, 25].

In the current study, multidrug resistance (MDR) bacterial isolate showed $75 \%$ and $82.5 \%$ resistance to Gramnegative and Gram-positive bacteria, respectively; this is in line with a study done in Addis Ababa [3]. Several reasons could have supported such level of resistance; this includes mismanagement of drugs by health specialists, unexperienced experts, and untrained individuals. In addition to this, most drugs in the study area can be bought deprived of laboratory confirmation, which leads to misuse of drugs by the community and thus causes the occurrence and spread of antibacterial tolerance. Additional fundamental reason could be reduced hospital sanitation, contributing to the spread of those drug-resistant bacteria in the area [24, 25]. This situation raises serious concerns. Moreover, the development of high resistance gene pool may increase antibacterial resistance. Taken together, these findings clearly show how resistance strains are expanding at an alarming rate in the area. With this trend, an antibiotic that was effective a year ago might no longer be used. This creates great burden, especially 


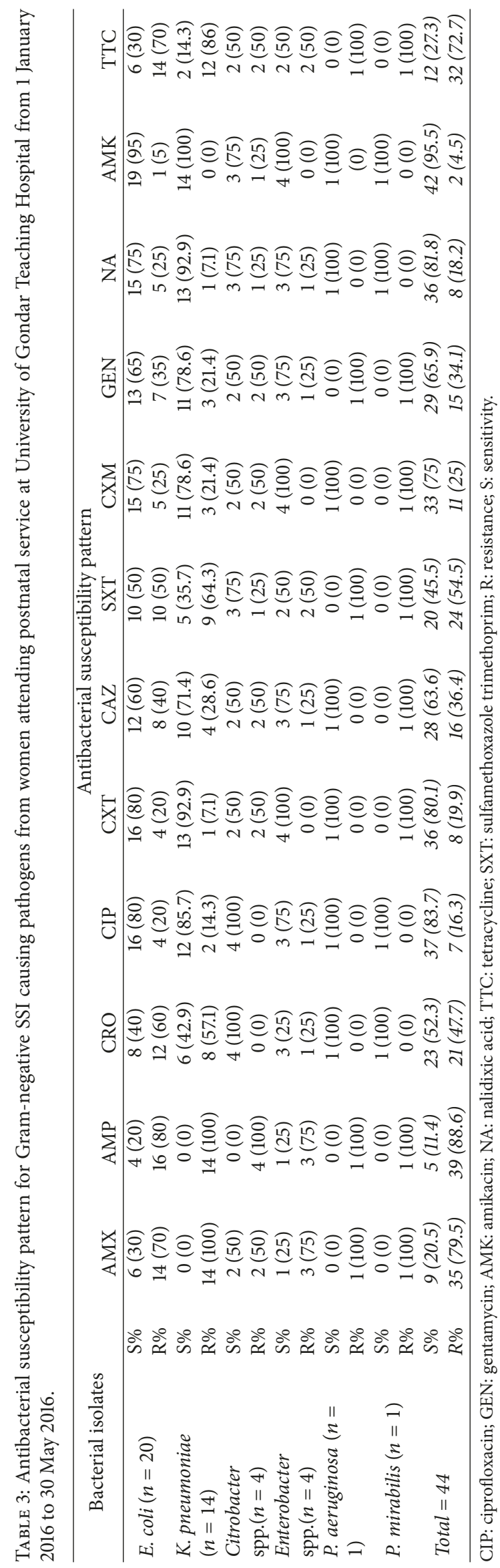


TABLE 4: Multidrug resistance (MDR) of Gram-negative and Gram-positive bacterial isolates from women attending antenatal and postnatal service.

(a)

\section{Gram-negative bacterial isolates}

Antibiograms

E. coli K. pneumoniae Citrobacter spp. Enterobacter spp. P. mirabilis P. aeruginosa

\begin{tabular}{|c|c|c|c|c|c|c|c|}
\hline & Total $=44$ & $=20$ & $=14$ & $=(4)$ & $=(4)$ & $=1$ & $=1$ \\
\hline AMP, TTC & $5(11.4)$ & $2(10)$ & $3(21.4)$ & - & - & - & - \\
\hline AMO, SXT & $1(2.3)$ & - & $1(11.1)$ & - & - & - & - \\
\hline AMP, TTC, GEN & $1(2.3)$ & $1(5)$ & - & - & - & - & - \\
\hline AMP, TTC, SXT & $3(6.8)$ & $1(5)$ & $2(14.3)$ & - & - & - & - \\
\hline AMO, SXT, CRO & $1(2.3)$ & $1(5)$ & - & - & - & - & - \\
\hline AMX, TTC, CRO & $1(2.3)$ & $1(5)$ & - & - & - & - & - \\
\hline AMX, TTC, CRO & $1(2.3)$ & $1(5)$ & - & - & - & - & - \\
\hline AMX, CRO, GEN, TTC & $1(2.3)$ & $1(5)$ & - & - & - & - & - \\
\hline AMX, TTC, SXT, CRO & $5(11.4)$ & $1(5)$ & $2(14.3)$ & - & $1(25)$ & - & $1(100)$ \\
\hline AMP, SXT, CRO, NAL & $2(4.5)$ & $2(10)$ & - & - & - & - & - \\
\hline AMO, SXT, CXM, TTC & $1(2.3)$ & - & - & $1(25)$ & - & - & - \\
\hline AMO, CPR, CRO, NAL & $1(2.3)$ & $1(5)$ & - & - & - & - & - \\
\hline AMO, TTC, SXT, GEN, CRO & $4(9.1)$ & $1(5)$ & $3(21.4)$ & - & - & - & - \\
\hline AMO, CXM, AMK, TTC, NAL & $1(2.3)$ & - & - & $1(25)$ & - & - & - \\
\hline AMO, SXT, CXM, GEN, TTC & $1(2.3)$ & - & - & - & - & $1(100)$ & - \\
\hline AMO, CRO, CPR, SXT, TTC, NAL & $1(2.3)$ & $1(5)$ & - & - & - & - & - \\
\hline AMO, CPR, SXT, CXM, TTC, NAL & $1(2.3)$ & - & $1(11.1)$ & - & - & - & - \\
\hline AMO, CRO, CPR, SXT, GEN, TTC, NAL & L $3(6.8)$ & $2(10)$ & - & - & $1(25)$ & - & - \\
\hline Total & $33(75)$ & $15(75)$ & $12(85.7)$ & $2(50)$ & $2(50)$ & $1(100)$ & $1(100)$ \\
\hline
\end{tabular}

(b)

\begin{tabular}{lccc}
\hline Antibiograms & \multicolumn{2}{c}{ Gram-positive bacterial isolates } \\
& Total $=57$ & S. aureus $=42$ & - \\
P, CXM & $1(1.8)$ & $1(2.4)$ & $1(7.7)$ \\
P, CRO & $1(1.8)$ & - & $1(7.7)$ \\
AMP, CXC & $2(3.5)$ & $1(2.4)$ & $1(7.7)$ \\
AMP, CAZ & $2(3.5)$ & $1(4.8)$ & $1(7.7)$ \\
AMO, SXT & $6(10.5)$ & $5(11.9)$ & - \\
P, CRO, SXT & $1(1.8)$ & $1(2.4)$ & $2(15.4)$ \\
AMP, SXT, CAZ & $3(5.3)$ & $1(2.4)$ & - \\
AMO, CAZ, CXC & $3(5.3)$ & $3(7.1)$ & - \\
AMO, CRO, CXC & $4(7)$ & $4(9.5)$ & - \\
AMO, CRO, SXT & $2(3.5)$ & $2(4.8)$ & $1(7.7)$ \\
AMP, SXT, CXC & $2(3.5)$ & $1(2.4)$ & - \\
P, SXT, CXC, CD & $2(3.5)$ & $2(4.8)$ & $2(15.4)$ \\
P, CRO, SXT, CXC & $6(10.5)$ & $4(9.5)$ & $1(7.7)$ \\
AMP, CAZ, SXT, CXC & $4(7)$ & $2(4.8)$ & - \\
AMP, CRO, CXC, SXT & $3(5.3)$ & $3(7.1)$ & - \\
P, CRO, SXT, CXC, DA & $1(1.8)$ & $1(2.4)$ & - \\
P, SXT, CAZ, CXC, DA & $2(3.5)$ & $1(2.4)$ & $1(7.7)$ \\
AMO, CRO, SXT, CXC, DA & $2(3.5)$ & $2(4.8)$ & - \\
\hline Total & $47(82.5)$ & $35(83.3)$ & $11(84.6)$ \\
\hline
\end{tabular}

TTC: tetracycline; GEN: gentamycin; NA: nalidixic acid; CPR: ciprofloxacin; CoNS: coagulase negative Staphylococcus species; GAS: group A Streptococcuspyogenes; CD: clindamycin; CXC: cloxacillin. 
TABLE 5: Bivariate and multivariate analysis for the assessment of factors associated with bacterial infection from women attending antenatal and postnatal service at the University of Gondar Teaching Hospital from 1 January 2016 to 30 May 2016.

\begin{tabular}{|c|c|c|c|c|c|}
\hline \multirow{2}{*}{ Characteristics } & \multicolumn{2}{|c|}{ Culture } & \multirow{2}{*}{$\begin{array}{c}\text { Bivariate analysis } \\
\text { COR }(95 \% \mathrm{CI})\end{array}$} & \multirow{2}{*}{$\begin{array}{c}\text { Multivariate analysis } \\
\text { AOR }(95 \% \mathrm{CI})\end{array}$} & \multirow{2}{*}{$p$ value } \\
\hline & Positive number (\%) & Negative number (\%) & & & \\
\hline \multicolumn{6}{|l|}{ Age } \\
\hline $15-24$ & $34(37.8)$ & $5(29.4)$ & 1 & & \\
\hline $25-34$ & $49(54,4)$ & $7(41.2)$ & $2.267(0.454,11.327)$ & & \\
\hline $35-44$ & $7(7.8)$ & $5(29.4)$ & $1.741(0.393,7.713)$ & & \\
\hline \multicolumn{6}{|l|}{ Residence } \\
\hline Urban & $70(77.8)$ & $13(76.5)$ & $0.923(0.273,3.164)$ & & \\
\hline Rural & $20(22.2)$ & $4(23.5)$ & 1 & & \\
\hline \multicolumn{6}{|l|}{ Occupation } \\
\hline Self-employer & $85(94,4)$ & $17(100)$ & 1 & & \\
\hline Government & $5(5.6)$ & $0(0)$ & $0.982(0.585,1.648)$ & & \\
\hline \multicolumn{6}{|l|}{ Education } \\
\hline Illiterate & $28(31.1)$ & $7(41.2)$ & 1 & & \\
\hline Primary & $12(13.3)$ & $2(11.8)$ & $0.696(0.181,2.674)$ & & \\
\hline Secondary & $27(30)$ & $4(23.5)$ & $1.043(0.167,6.59)$ & & \\
\hline Higher education & $23(25.6)$ & $4(23.5)$ & $1.174(0.264,5.226)$ & & \\
\hline \multicolumn{6}{|l|}{ Marital status } \\
\hline Married & $88(97.8)$ & $17(100)$ & 1 & & \\
\hline Single & $2(2.2)$ & $0(0)$ & $0.691(0.227,2.101)$ & & \\
\hline \multicolumn{6}{|l|}{ Mode of delivery } \\
\hline VDE & $34(37.8)$ & $3(17.6)$ & $15.111(3.095,73.77)$ & $102(5.2,2028)$ & 0.002 \\
\hline $\mathrm{C} / \mathrm{S}$ & $50(55.6)$ & $6(35.3)$ & $11.111(2.865,43.099)$ & $86(5,1436)$ & 0.002 \\
\hline Instrumental & $6(6.7)$ & $8(47.1)$ & 1 & & \\
\hline \multicolumn{6}{|l|}{ Prolonged labour } \\
\hline No & $45(50)$ & $10(58.8)$ & 1 & & \\
\hline Yes & $45(50)$ & $7(41.2)$ & $0.700(0.245,2.001)$ & & \\
\hline \multicolumn{6}{|l|}{ PRM } \\
\hline No & $50(55.6)$ & $14(82.4)$ & 1 & & \\
\hline Yes & $40(44.4)$ & $3(17.6)$ & $0.268(0.072,0.997)$ & $0.012(0.001,0.305)$ & 0.008 \\
\hline \multicolumn{6}{|l|}{ Gravidity } \\
\hline $1-3$ & $80(88.9)$ & $15(88.2)$ & $1.746(0.513,5.940)$ & & \\
\hline $4-6$ & $9(10)$ & $1(5.9)$ & $1.290(0.343,4.856)$ & & \\
\hline $7-9$ & $1(1.1)$ & $1(5.9)$ & 1 & & \\
\hline
\end{tabular}

Note. $*$ indicates statistical significance at $p \leq 0.05$, in both bivariate and multivariate analyses. AOR: adjusted odds ratio; COR: crude odds ratio; 1 : reference group; 95\% CI: 95\% confidence interval; UTI: urinary tract infection; C/S: cesarean section; VDE: vaginal delivery with episiotomy; PRM: premature rapture of membrane.

to people living in resource-poor countries, where they could not ensure their daily bread let alone for medication. The cost of new antibiotics is also high, which in turn poses great burden for poor countries [27].

In addition to the identification of the common bacteria and their resistance pattern, this study tried to evaluate the association of different sociodemographic and clinical parameters with bacterial infection. In the present study, the prevalence of bacteria was associated with obstetric parameters like mode of delivery through cesarean section and vaginal delivery by using episiotomy $(p=0.002)$. This could be attributed to the physiological change, immune shift, high bleeding, and contamination; this is in line with studies conducted in Bahir Dar [9], Jimma [4, 14], and Estonian University [10]. There was also an association of developing bacterial infection with premature rapture of membrane $(p=0.018)$. This is in line with studies conducted in Jimma [4], Tanzania [11], Hong Kong [28], and Brazil [29]. This might be due to the fact that having a premature rapture of membrane could expose women to various injuries, which again enable pathogenic bacteria to have suitable environment to cause infection. The presence of wound infection following cesarean section and episiotomy was aggravated due to improper wound care and improper treatment. In addition, women who have got premature rapture of membrane could get exposed to various injuries and minor tears, which again enable pathogenic bacteria to have convenient environment to cause infection.

The limitation of anaerobic culture facility that is used to cultivate anaerobic bacteria might increase the quantity of 
bacterial identification. Since it is a cross-sectional study, it has limited capacity to assess risk factors.

\section{Conclusion and Recommendations}

The prevalence of bacterial infection was too increased among women who attended postnatal care. The major bacteria were S. aureus, E. coli, CoNS, K. pneumoniae, Citrobacter, Enterobacter, and S. pyogenes. Gram-negative and Grampositive bacteria revealed resistance to the most frequently used drugs tested in vitro. Multidrug-resistant bacteria show big threat posed by antibiotic resistant strains in vulnerable mothers. Drug-resistant bacterial infection leads to increased patient hospital stay, health care costs, and death rate. Factors such as cesarean section, episiotomy for delivery, and premature rapture of membrane were predictors for bacterial infection among postnatal mothers. Reviewing the nature and cause of bacterial infection and its drug resistance is necessary to overcome bacterial infection. To confirm applicable treatment, the existing information about bacteria that cause maternal infections and their drug resistance pattern is essential.

\section{Conflicts of Interest}

The authors declare that there are no conflicts of interest regarding the publication of this study.

\section{Acknowledgments}

The study was funded by Armauer Hansen Research institute. The authors thank study members for volunteering to give a specimen and Dr. Dawit Kassahun. They also would like to thank Professor Feleke Moges, Department of Medical Microbiology, University of Gondar, and Gondar University Teaching Hospital. Finally, they want to acknowledge Amhara Health Bureau, Armauer Hansen Research Institute, and Federal Ministry of Health.

\section{References}

[1] S. M. Pear, "Patient Risk Factors and Best Practices for Surgical Site Infection Prevention," in Managing Infection Control, p. 56, 2007.

[2] W. Dessie, G. Mulugeta, S. Fentaw, A. Mihret, M. Hassen, and E. Abebe, "Pattern of bacterial pathogens and their susceptibility isolated from surgical site infections at selected referral hospitals, Addis Ababa, Ethiopia," International Journal of Microbiology, vol. 2016, Article ID 2418902, 8 pages, 2016.

[3] D. Amenu, T. Belachew, and F. Araya, "Surgical site infection rate and risk factors among obstetric cases of Jimma University Specialized Hospital, Southwest Ethiopia," Ethiopian Journal of Health Sciences, vol. 21, no. 2, pp. 91-100, 2011.

[4] J. Amatya, M. Rijal, and R. Baidya, "Bacteriological study of the postoperative wound samples and antibiotic susceptibility pattern of the isolates in BB hospital," The Journal of Sexual Medicine, vol. 3, no. 1, p. 1019, 2015.

[5] K. Conroy, A. F. Koenig, Y. Yan-Hong, A. Courtney, H. J. Lee, and E. R. Norwitz, "Infectious morbidity after cesarean delivery: 10 Strategies to reduce risk," Reviews in Obstetrics \& Gynecology, vol. 5, pp. 69-77, 2012.
[6] DM. Kabau, S. Wanjala, and F. Kagema, "Incidence and determinants of surgical site infection after Caesarean Delivery at Kenyatta National Hospital," Incidence and determinants of surgical site infection after Caesarean Delivery at Kenyatta National Hospital, p. 51, 2014.

[7] P. Mitt, K. Lang, A. Peri, and M. Maimets, "Surgical-site infections following cesarean section in an Estonian University Hospital: Postdischarge surveillance and analysis of risk factors," Infection Control and Hospital Epidemiology, vol. 26, no. 5, pp. 449-454, 2005.

[8] F. Kasolo, A. A. Yahaya, J. B. Ndihokubwayo, B. Impouma, C. J. Oxenford, and S. Cognat, "Guide for establishing laboratorybased surveillance for antimicrobial resistance; World Health Organization Regional Office for Africa," Guide for establishing laboratory-based surveillance for antimicrobial resistance, pp. 125, 2013.

[9] W. Mulu, G. Kibru, G. Beyene, and M. Damtie, "Postoperative nosocomial infections and antimicrobial resistance pattern of bacteria isolates among patients admitted at Felege Hiwot Referral Hospital, Bahirdar, Ethiopia," EthiopianJournal of Health Sciences, vol. 22, no. 1, pp. 7-18, 2012.

[10] J. Neu and J. Rushing, "Cesarean versus vaginal delivery: longterm infant outcomes and the hygiene hypothesis," Clinics in Perinatology, vol. 38, no. 2, pp. 321-331, 2011.

[11] B. H. Rimawi, Infectious Comorbidities Encountered in Obstetrics and Neonatology, OMICS International, 2014, http://www .esciencecentral.org/ebooks.

[12] R. Simões, R. C. Cavalli, W. M. Bernardo, A. J. Salomão, and E. C. Baracat, "Cesarean delivery and prematurity," Revista da Associação Médica Brasileira, vol. 61, no. 6, pp. 489-494, 2015.

[13] G. Adwan, N. Abu Hasan, I. Sabra, D. Sabra, S. Al-butmah, and S. Odeh, "Detection of bacterial pathogens in surgical site infections and their antibiotic sensitivity profile," International Journal of Medical Research and Health Sciences, vol. 5, no. 5, pp. 75-82, 2016, http://www.ijmrhs.com.

[14] T. Sahile, S. Esseye, G. Beyene, and S. Ali, "Post-surgical Infection and Antibiotic Susceptibility Patterns of Bacteria Isolated from Admitted Patients with Signs of Infection at Jimma University Specialized Hospital, Jimma, Ethiopia," International Journal of TROPICAL DISEASE \& Health, vol. 17, no. 4, pp. 1-12, 2016.

[15] L. Charrier, P. Serafini, A. Ribatti, A. Castella, G. Rabacchi, and C. M. Zotti, "Post-partum surgical wound infections: Incidence after caesarean section in an Italian hospital," Journal of Preventive Medicine and Hygiene, vol. 50, no. 3, pp. 159-163, 2009.

[16] R. Cooper, "Practice development how to take a wound swab," Wounds International, vol. 1, no. 3, pp. 19-20, 2010.

[17] S. E. Gardner, R. A. Frantz, C. L. Saltzman, S. L. Hillis, H. Park, and M. Scherubel, "Diagnostic validity of three swab techniques for identifying chronic wound infection," Wound Repair and Regeneration, vol. 14, no. 5, pp. 548-557, 2006.

[18] Clinical and Laboratory Standards Institute, Performance standards for antimicrobial susceptibility testing: twenty-fourth informational supplement M100-S24, CLSI, Wayne, PA, USA, 2016.

[19] V. Filippi, D. Chou, C. Ronsmans, W. Graham, and L. Say, Levels and Causes of Maternal Morbidity and Mortality, chapter 3, 1-31, 2013.

[20] S. Sriskandan, "In infectious diseases, national centre for infection prevention and management, department of infectious diseases immunity, imperial college London, UK," $J R$ Coll Physicians Edinb, vol. 41, pp. 339-46, 2011. 
[21] O. Issa, EC. Mgongo, and J. W. Gichuhi, "Post caesarean section wound sepsis at mnazi mmoja hospital Zanzibar," Journal of Obstetrics and Gynaecology, pp. 1-9, 2010.

[22] F. J. Mpogoro, S. E. Mshana, M. M. Mirambo, B. R. Kidenya, B. Gumodoka, and C. Imirzalioglu, "Incidence and predictors of surgical site infections following caesarean sections at Bugando Medical Centre, Mwanza, Tanzania," Antimicrobial Resistance and Infection Control, vol. 3, no. 1, article no. 25, 2014.

[23] H. Dhar, I. Al-Busaidi, B. Rathi, A. Nimre, V. Sachdeva, and I. Hamdi, "A Study of Post-Caesaren Section Wound Infections in a Regional Referral Hospital Oman," SQU Medical Journal, vol. 14, no. 2, pp. 212-216, 2014.

[24] B. Amare, Z. Abdurrahman, B. Moges, and J. Ali, "Postoperative surgical site bacterial infections and drug susceptibility patterns at Gondar University Teaching Hospital, Northwest Ethiopia," Journal of Bacteriology \& Parasitology, vol. 2, no. 8, 2011.

[25] T. Frieden, Communicable Disease Control (CDC): Antibiotic Resistance threats in the United States, 2013.

[26] R. E. Mengesha, B. G.-S. Kasa, M. Saravanan, D. F. Berhe, and A. G. Wasihun, "Aerobic bacteria in post surgical wound infections and pattern of their antimicrobial susceptibility in Ayder Teaching and Referral Hospital, Mekelle, Ethiopia," BMC Research Notes, vol. 7, no. 1, article 575, 2014.

[27] H. Inoue and R. Minghui, "Antimicrobial resistance: translating political commitment into national action," Bulletin of the World Health Organization, vol. 95, no. 4, pp. 242-242, 2017.

[28] W. W. Y. Lam, "Abdominal wound infection after caesarean delivery in a district Hospital at University of Hong Kong," $H K U$ Scholars Hub, pp. 3-75, 2006.

[29] T. C. F. Farret, J. Dallé, V. da Silva Monteiro, C. V. W. Riche, and V.S. Antonello, "Risk factors for surgical site infection following cesarean section in a Brazilian Women's Hospital: A casecontrol study," The Brazilian Journal of Infectious Diseases, vol. 19, no. 2, pp. 113-117, 2015. 


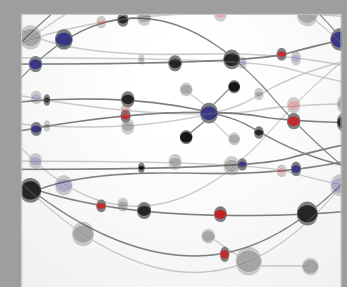

The Scientific World Journal
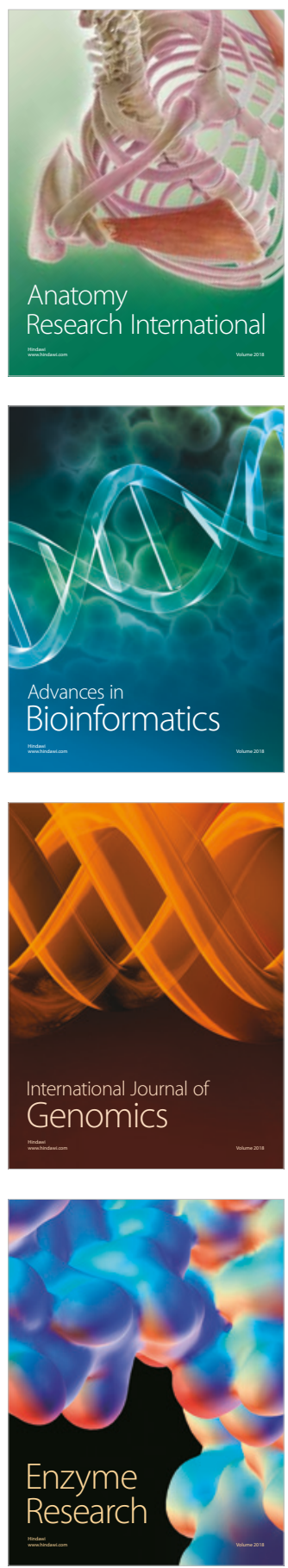
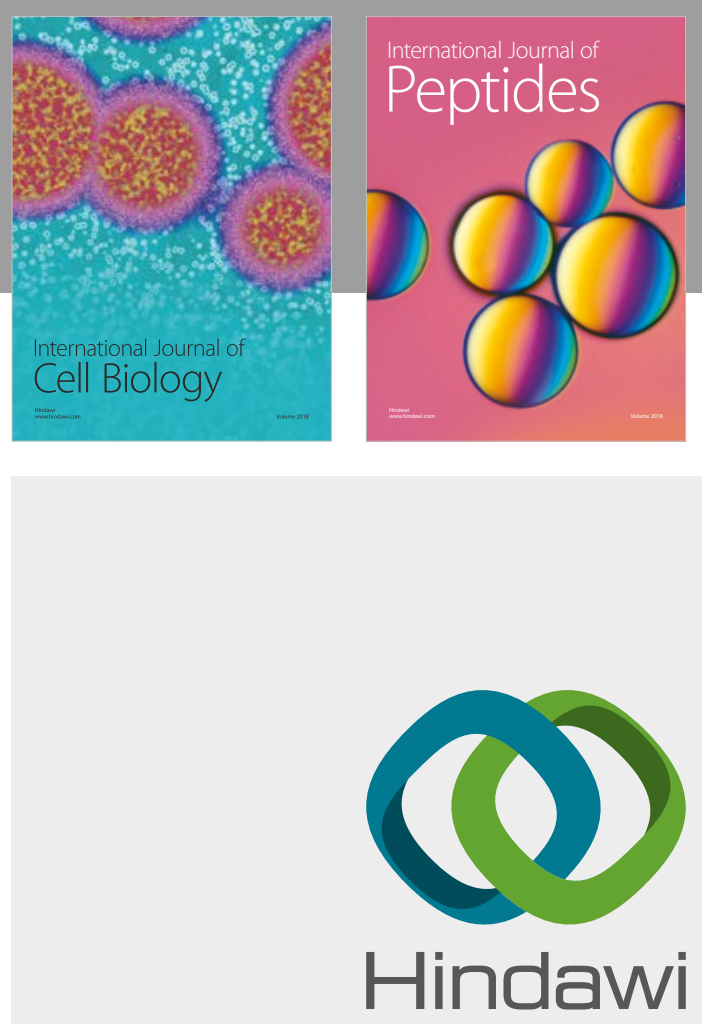

Submit your manuscripts at

www.hindawi.com
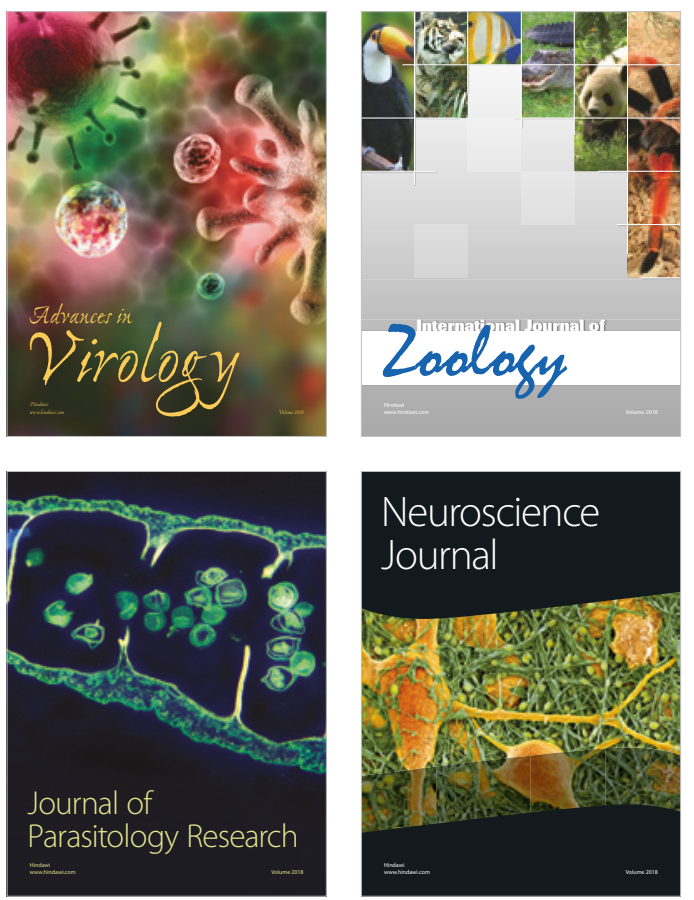
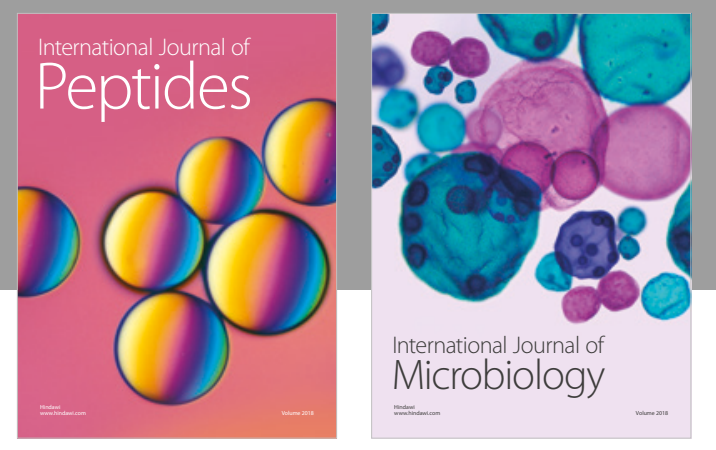

nternational Journal of Microbiology
Journal of
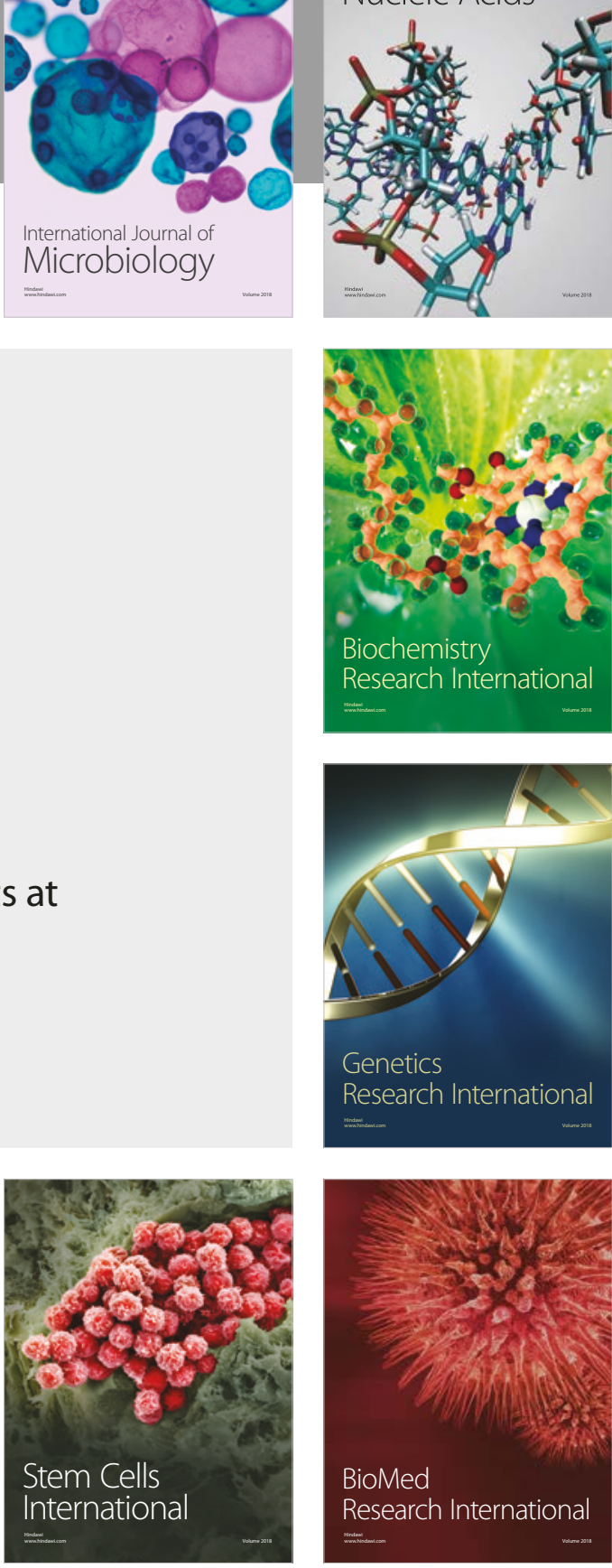
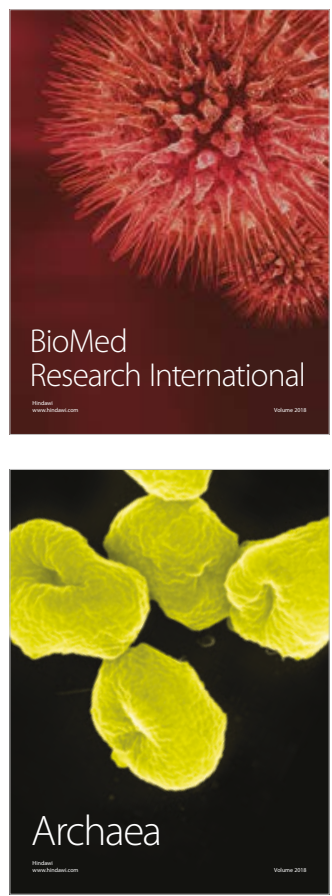